\title{
A Methodology to Determine the Economically Feasible Capacity for Rural Demand Response Transit Systems
}

Adam B. Sandlin, Tennessee Department of Transportation Michael D. Anderson, University of Alabama, Huntsville

\section{Abstract}

Transportation professionals generally use volume-to-capacity ratios as a standard measure of effectiveness to evaluate the operation of transportation facilities. Unfortunately, this commonly used measure has not been available for the analysis of rural demand response transit systems, as there has not been a clearly defined methodology for determining the capacity of these systems. This article presents a methodology for determining the capacity of a rural demand response transit system using an economic constraint model and spatial data for the service area stored in a Geographic Information System (GIS). The methodology develops an equation that incorporates operating costs, transit need, route distance, and revenue to define an agency's potential service area, or capacity. To demonstrate the methodology, the article presents a case study for a transit agency in Northwest Alabama. The article concludes that the methodology presented can be applied to determine the economically feasible service area for a rural demand response transit system, thus allowing for development and use of volume-to-capacity ratios as a consistent measure of effectiveness to evaluate an agency's operation. 


\section{Introduction}

Generally, transportation infrastructure analysis uses standard volume-to-capacity ratios, where demand for or use of the facility is taken as volume and maximum allowable use, based on the design of the facility (Highway Capacity Manual 1994). The volume-to-capacity ratio is used as a convenient measure of effectiveness to determine the level at which the facility is operating. For roadways, the relationships for determining volume and capacity have been studied to the extent that few questions arise when attempting to determine either volume or capacity for a given highway facility.

The easily understood relationship between volume and capacity in transportation, however, has been difficult applying to rural passenger transit systems because of the lack of a clear methodology for determining the capacity of a demand response transit system. This lack of a clear methodology has been documented in the recently-released Transit Capacity and Quality of Service Manual (TCQSM) (TCQSM 1999).

In an attempt to provide a methodology, this article presents a GIS-based methodology for determining the economically feasible capacity, or maximum service extent, for a rural passenger transit system, which can be used to calculate a volume-to-capacity ratio. The methodology is designed for rural demand response transit agencies that have a centralized vehicle storage facility in an urban area and a daily operation in which the vehicles travel to pick up passengers in the rural areas and bring them to services available in the urban area. The methodology presented focuses on initially determining the total area that the rural transit agency would be able to provide service to without losing money; the later portion of the methodology identifies the percent of the total area that can be serviced with the existing fleet. The article presents a case study using a rural transit agency in Northwest Alabama to demonstrate the methodology and concludes that the GIS-based methodology represents an effective method to determine capacity of and maximum service extent for rural passenger transit systems.

\section{Methodology}

The TCQSM presents the notion that "a demand-responsive vehicle's person capacity is inversely related to the size of its service area and also inversely related to the number of potential origins and destination it must serve" (TCQSM 1999, p. 68). The manual also identifies the use of peer agencies as the best method for determining person capacity. 
In contrast to the TCQSM, this article does not define capacity in terms of the number of passengers that can be moved by the existing fleet but focuses on the service area that the agency can economically serve. The basis for the methodology presented here is the economic notion of diminishing returns. By definition, the point of diminishing returns is the point at which providing transit service to a larger area causes a decrease in the overall trip rate, resulting in an inefficient operation (Spielberg et al. 1995). This point will be referred to as the maximum service criterion. The methodology defines the variables necessary for calculating the maximum service extent and presents a series of GIS-based steps to complete the calculation.

The variables needed to define the service criterion are operational costs, transit need, charge for transportation services, and distance to each stop. The operational costs are to be obtained from the agency being studied. If, for some reason, this information is not available, operating costs can be estimated after examination of similar transit agencies serving similar areas. For this analysis, it is necessary to develop a single cost rate to serve as operating costs. The operating costs, which include all administrative and maintenance fees, should be calculated on a costper-mile basis.

Transit need can be determined in different ways, depending on available data and/or the particular study area (U.S. Department of Transportation 1990). The most widely accepted method to determine transit need is to use a profile of the population who represent those individuals most likely to use transit service (Mazur et al. 2001). For the case study presented in this article, the transit need was determined through a combination of number of people older than 65 and number of households without a vehicle in the study area. Although other definitions of transit need can be used or other variables can enter the equation, there must be consistency in determining transit need between agencies that are being evaluated against each other.

The charge for transportation service is easily understood. This represents the total cost paid for the transportation service, including both the fare charged to the passenger and any subsidy allotted for the service. The cost for transportation service should be obtained from agency and/or State Department of Transportation records.

The distance to each stop is defined as total distance from the vehicle storage location to each passenger pick-up location. To ease the number of calculations when 
determining the distance to each stop, it is recommended that the center of each given area where transit need is determined be used. For the case study, this location is the center of the census block group upon which the transit need is determined. The distance to each stop is to be determined using either a GIS or other service area map.

\section{Procedures}

The following sections examine the five-step GIS-based procedure.

\section{Step 1. Collect Data Necessary for the Analysis.}

The initial step is to collect the data necessary for the analysis. GIS-based data requirements include roadway locations and census demographics for the study area. A possible source for the data is the U.S. Census Department Internet site or similar website. Typically the data will be segmented to individual county boundaries, not necessarily covering the entire study area. If the agency study area covers more than one county, the GIS-based data need to be merged into a single coverage. The charge for transportation service should also be collected from the agency of interest or State Department of Transportation.

\section{Step 2. Determine Maximum Service Criterion}

The second step is to determine the maximum service criterion, defined as the point when the distance necessary to travel to pick up another passenger becomes cost-ineffective. This maximum service criterion is derived from the following:

- Cost to operate service to a given location:

Per mile operating costs for the vehicle * total distance of the route

- Revenue generated from the service:

Number of riders * equivalent farebox fee

- To be economically feasible, the revenue must exceed the costs.

Therefore, the maximum service criterion is defined as:

$$
\left(\frac{\text { distance of route }}{\# \text { of transit riders/route }}\right) *\left(\frac{\text { operating cost/distance }}{\text { equivalent farebox fee }}\right) \leq 1
$$

where:

- Distance of route represents the pick up and return to the urban area.

- Distance is in miles and operating costs are in dollars. 
Using this equation, it is possible to identify route pick-up locations that are of a great distance and so few riders that they are not cost effective and therefore represent locations out of the agency's economically feasible capacity.

\section{Step 3. Determine Transit Need}

Transit need, as defined earlier, represents the number of individuals who potentially need transit service. For this step, the census data are suggested as a baseline socioeconomic dataset for the area of interest. From the census data, at the blockgroup level, it is possible to determine the number of elderly individuals, number of individuals living below selected poverty levels, and number of individuals without private automobiles - all of which might be used to determine the number of potential transit riders. For this step, it is necessary for the agency to identify the method it intends to use to determine transit ridership characteristics of its particular service area.

For an example of the determination of transit need using census block-group data, determine the percent of households without vehicles and the percent of the population more than 65 years old. Making the generalized assumption that the percent of people without automobiles is constant for all age categories, multiply these two values and then multiply the total population of the block group to estimate the population over age 65 and without vehicles. This value can then be used as one estimate of the population within each block group that needs public transportation. This number, however, is an estimate of the transit need and many additional factors could be used to determine the transit need for a selected area [e.g., the National Personal Transportation Survey (NTPS) or other transportation-related data].

\section{Step 4. Determine Distance from Storage Location to Block-Group Centroids}

After determining the transit need based on the census data block groups, the next step is to determine the distance from the storage facility where the vehicle trip originates to the pick-up locations where passengers are assumed to be waiting. The use of GIS is almost necessary for successfully completing this step in a timely manner. Using the functionality available in most GIS software packages, it is possible to determine the coordinates of the block-group centroids (i.e., locations where passengers are to be picked up). Then, also using functionality available in most GIS software packages, it is possible to determine the shortest distance from the storage facility to the centroid along the shortest path. Although this step is possible without using GIS, the determination of the block-group cen- 
troid would have to be performed using visual interpolation methods and the shortest-route distance would then need to be calculated manually-both actions are timely and have great potential for error.

\section{Step 5. Determine Block Groups that Are Within Maximum Service Criterion}

At this point, with the transit need and distance from storage facility to all stops described, it is possible to identify those stops within the maximum service criterion. Again, using the relationship,

$\left(\frac{\text { distance of route }}{\# \text { of transit riders/route }}\right) *\left(\frac{\text { operating cost/distance }}{\text { equivalent farebox fee }}\right) \leq 1$

it is possible to determine these stop locations. This information now provides the maximum service extent (or total capacity) for the transit area to provide service without losing money as a result of the service.

This determination also provides a total transit need that the agency should attempt to serve. Unfortunately, this total transit need is developed independent of vehicle fleet size and most agencies will not be able to serve the entire transit need with their existing fleet. Using the total transit need, however, provides a method for determining the total number of vehicles necessary to provide service to the entire population by dividing need by occupancy per vehicle. When taking into account the actual number of vehicles operated by an agency, it is possible to determine a modified capacity by allocating vehicles in the most cost-effective manner (i.e., starting with short routes that have high ridership). In this manner, it is possible to determine a modified capacity for the agency, which is a factor of the total capacity.

The final step of the analysis would be the determination of a volume-to-capacity ratio for the agency, in which the volume would represent an average number of people served per day divided by the capacity of transit needs based on the agency fleet. In this manner, different agencies could then be compared using a single standard measure of effectiveness.

\section{Case Study}

To aid in understanding the methodology presented, a case study has been performed for an agency serving the two-county region covering Lauderdale and 
Colbert Counties, Alabama. The urban center for the region is the combination of four Alabama communities: Florence, Muscle Shoals, Sheffield, and Tuscumbia, known collectively as the Shoals. The area is home to 136,572 people, with 15 percent of the population more than 65 years old (www.census.gov 2001).

\section{Step 1. Collect Data Necessary for the Analysis}

Roadway and census data at the block-group level were downloaded from the Internet and brought into the GIS environment. For the case study, the data were downloaded from www.geographynetwork.com and the GIS program used was ArcView (ESRI Inc.). The data downloaded from the Internet were segmented by county level, and the GIS program was used to develop a single coverage for roadways and census demographics for the two-county area.

In addition to the roadways and census demographics, operational costs and charges for transportation services were obtained from the transit agency directly. Operational costs were determined to be $\$ 0.50 / \mathrm{mile}$ and $\$ 7.00 /$ hour. The agency also noted that the average speed for any bus traveling throughout the network was 10 mph (NACOLG Transit Representatives 2001). Assuming that these costs include all administrative and maintenance fees, operational costs were determined to be $\$ 1.20$ per mile.

Regarding the charge for transit service, an assumption was made in this case study that the transit agency would be responsible for collecting 35 percent of the total operational costs from farebox revenue, with the other 65 percent coming from local or federal funds. For the agency studied, the farebox charge was $\$ 1.25$ per trip, making the total charge for transit service $\$ 3.57$ per trip.

\section{Step 2. Determine Maximum Service Criterion}

As noted above, the definition of capacity used in this article is the service area that can be covered by the agency without losing money as a result of providing the service. This was defined previously as:

$$
\left(\frac{\text { distance of route }}{\# \text { of transit riders/route }}\right) *\left(\frac{\text { operating cost/distance }}{\text { equivalent farebox fee }}\right) \leq 1
$$

Solving this inequality for the case study agency using an operating cost/distance of $\$ 1.20 /$ mile and an equivalent farebox fee of $\$ 3.57$ yields: 


\section{$\frac{\text { distance of route }}{\# \text { of transit riders/route }} \leq 2.975=$ service criteria}

This measure implies that service should be offered, essentially defining the area that should encompass the agency's capacity, if the ratio between the distance to the riders and the number of riders is less than 2.975. This inequality takes into account zones with high transit needs that are a considerable distance form the central bus facility, making them good candidates for transit service.

\section{Step 3. Determine Transit Need}

The transit need for the case study agency was determined using census blockgroup data for the two-county area downloaded in the first step. The transit need was determined as the number of people in the block group age 65 and older multiplied by the percentage of the block group without automobiles. This was performed, in GIS and there were 100 stops calculated to have at least one potential transit rider to service as transit need. For simplicity, all block groups without a single transit rider were deleted from the theme.

\section{Step 4. Determine Distance from Storage Location to Block-Group Centroids}

Distances from the central bus storage facility to passengers in the block groups were determined using GIS. A point theme for the agency's central bus facility and census block-group centroids, to serve as pick-up locations for the areas, was created in ArcView. The agency's facility was created using the geocode address feature in ArcView representing the point of origin of all bus routes. The "Get coordinate table" extension for ArcView was used to create a point theme for the centroids of each block group to simulate transit stops. The block groups attribute table and the bus stops point theme were then joined, linking the location and transit need.

The shortest path from each point, including the origin, as defined by distance, to all the other points was determined using the Network Analyst and Shortest Network paths extension (see Figure 1). The bus stops table and the new network's attribute table, created using the Shortest Network path extension, were then joined to calculate the cost associated with traveling to each pick-up location, using the $\$ 1.20$ per mile operating cost developed earlier. 


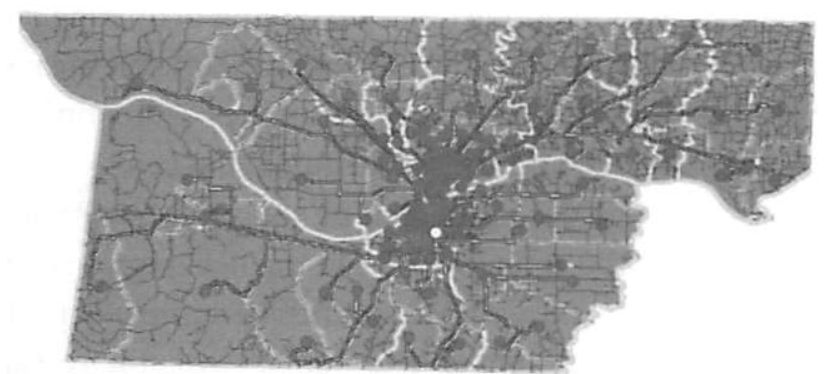

Figure 1. All pick-up locations and shortest routes

\section{Step 5. Determine Block Groups that Are Within Maximum Service Criterion}

Using the service criterion as cost, setting the cut-off value at 2.976 as defined previously, and specifying the agency's bus facility as the origin, GIS was used to identify pick-up locations that can be reached where passengers available divided by the distance is less than 2.975 . The service area could quickly be identified as a region to better understand the capacity for the particular agency (see Figure 2).

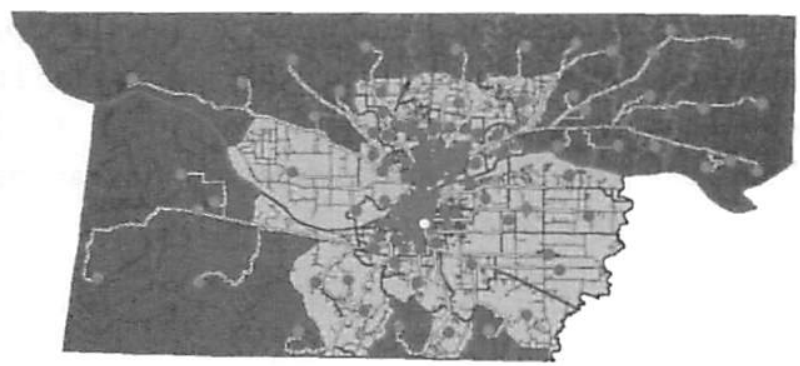

Figure 2. Maximum service area for the case study

\section{Results}

The results of the case study identify that 70 of the 100 sites with transit riders are located outside the economically feasible capacity and, therefore, should not be included in the agency's capacity. The study also indicates that the agency's capacity includes 69 percent of the transit need for the two-county area, or 1,298 of 1,884 potential transit riders based on the definition of transit need used. This information implies that the agency would be able to accommodate all of the 1,298 
potential transit riders without losing money as a result of offering the service. The number of potential transit riders in the economically feasible area would require 87 vehicles (assuming 15 passengers per vehicle) in the fleet to move all passengers in a given day. Taking into account the actual number of vehicles operated by the agency, the capacity for the agency should be the total potential transit riders multiplied by the ratio of the actual vehicles in the fleet versus the total vehicles required to transport all riders. This value can then be compared to the number of passengers actually using the system to determine the volume-to-capacity ratio.

\section{Conclusions}

This article presents a methodology to determine the capacity of a rural transit agency using a methodology based on the economical limit of service and spatial data stored in a GIS. The methodology and GIS were used to identify all the locations where the number of potential passengers and the operating costs for the transit system allowed for inclusion in the maximum service criterion, or limits of capacity for the agency. The methodology can also be used to assist transit areas in determining their target market for advertising and publicity by identifying areas where there are a high number of potential riders and the distance or operating costs are low.

In general, the methodology presents one way to determine the capacity for rural demand response transit service. This calculation of capacity would thus allow for the development of commonly used volume-to-capacity ratios for different transit agencies. These agency-specific volume-to-capacity ratios can then be used as measures of effectiveness for evaluating rural demand response transit agencies. 


\section{References}

Highway capacity manual. 1994. Special Report 209, $3^{\text {rd }}$ ed. Washington, DC: Transportation Research Council.

Mazur, G. D., K. K. Dixon, and W. A. Sarasua. 2001. Multicriteria feasibility evaluation for rural transit in Georgia. Journal of Public Transportation 3 (4).

NACOLG Transit Representatives. 2001. Personal interview. July 18.

Spielberg, F., G. Shaw, and C. McGetrick. 1995. Workbook for estimating demand for rural passenger transportation. Washington, DC: Transit Cooperative Research Program Report.

Transit capacity and quality of service manual. 1999. Washington, DC: Transit Cooperative Research Program, Transportation Research Board, National Research Council.

U.S. Department of Transportation. 1990. Guidebook for planning small and rural transportation programs, vol. 1. Washington DC.

www.census.gov, accessed July 30, 2001.

\section{About the Authors}

ADAM B. SANDLIN (adamsan@hiwaay.net) is a graduate transportation associate at the Tennessee Department of Transportation where he works on a variety of civil engineering projects.

MiChAEL D. ANDERSOn (mikea@cee.uah.edu) is an assistant professor of civil engineering at the University of Alabama in Huntsville. His area of focus is on rural public transportation and transportation forecasting. 